\title{
Emerging therapies for treatment of multiple sclerosis
}

This article was published in the following Dove Press journal:

Journal of Inflammation Research

22 July 2010

Number of times this article has been viewed

John R Corboy

Augusto A Miravalle

Rocky Mountain Multiple Sclerosis Center, Anschutz Medical Campus, University of Colorado Denver,

Aurora, Colorado, USA
Correspondence: Augusto A Miravalle University of Colorado Denver, 12631 East 17th Avenue, BI85, Aurora, CO 80045, USA

Tel +I 3037242187

Fax +I 3037242202

Email augusto.miravalle@ucdenver.edu
Abstract: In the last decade, a new armamentarium of immune-based therapies have been developed and tested in patients with multiple sclerosis. Some of these therapies are showing a high level of efficacy, with an acceptable adverse effect profile. Because present therapies have significant limitations in slowing disease progression, require injections, are sometimes associated with significant side effects of immunosuppression, and do little to reverse disability, identifying more effective treatments is an important goal for clinical research in multiple sclerosis. However, in order to improve our current approach to disease-modifying therapies, it is imperative to promote the development of individualized therapy strategies.

Keywords: multiple sclerosis, lymphocyte-targeted therapy, immune sequestration, non-specific immune modulation

\section{Introduction}

Recent advances in our understanding of the immunopathogenesis of multiple sclerosis (MS) have generated the development of novel and promising neurotherapeutic strategies. This review summarizes the most updated data from recent Phase II/III clinical trials evaluating the clinical efficacy and safety of promising therapeutic interventions in MS patients (Table 1). Other potential side effects may come to light with more patients studied and greater use of these drugs.

\section{Lymphocyte-targeted therapy Cladribine}

Cladribine is a purine nucleoside analogue that produces lymphotoxic effects when incorporated into the DNA of resting and dividing cells with high deoxycytidine kinase activity (lymphocytes and monocytes), and subsequent interruption of DNA replication, DNA damage, and cell death. ${ }^{1}$ In addition to its lymphotoxic effects, cladribine possesses epigenetic properties, by inhibiting S-adenosyl homocysteine hydrolase and DNA methylation. ${ }^{2}$ It received FDA approval in the 1980 s for treatment of hairy cell leukemia.

Parenteral cladribine (total dose $2.8 \mathrm{mg} / \mathrm{kg}$ ) significantly reduced the number and volume of $\mathrm{T}_{1}$ gadolinium-enhancing lesions, accumulation of $\mathrm{T}_{2}$ lesion volume, relapse rate, and disability progression in patients with progressive and relapsing forms of MS. ${ }^{3-5}$ A dose-dependent increase in adverse events was observed, leading to selection of low doses for use in an ongoing clinical development program of an oral tablet formulation. 
Table I Selected emerging MS therapies

\begin{tabular}{|c|c|c|c|c|c|}
\hline $\begin{array}{l}\text { Lymphocyte-targeted } \\
\text { therapy }\end{array}$ & Mechanism of action & Route/Dose & Results & Status & AEDs \\
\hline Cladribine & $\begin{array}{l}\text { Purine nucleoside } \\
\text { analog }\end{array}$ & $\begin{array}{l}\text { Oral (3.5 and } \\
5.25 \mathrm{mg} / \mathrm{kg} \\
\text { total dose) }\end{array}$ & $\begin{array}{l}58 \% \downarrow R R, 43 \% \\
\text { disease free }\end{array}$ & Phase III & $\begin{array}{l}\text { HZV, lymphopenia, HA, } \\
\text { nasopharyngitis, } \\
\text { lymphopenia }\end{array}$ \\
\hline Alemtuzumab & Anti-CD52 & IV I2 mg dose/y & $\begin{array}{l}75 \% \downarrow \text { SAD (12 mg dose), } \\
74 \% \downarrow R R\end{array}$ & Phase III & $\begin{array}{l}\text { ITP (3 pts), Graves } \\
\text { disease }(20 \%)\end{array}$ \\
\hline Daclizumab & Anti-CD25/anti-IL2 & SQ 2 mg/kg (Q2w) & $\begin{array}{l}72 \% \downarrow \text { CEL in } \\
\text { RRMS patients }\end{array}$ & Phase II & $\begin{array}{l}\text { Skin rash, chest } \\
\text { discomfort, headaches, } \\
\text { lymphopenia }\end{array}$ \\
\hline Rituximab & Anti-CD20 & $\begin{array}{l}\text { IV (I gram } \\
\text { dose, Q2w, × 2) }\end{array}$ & $91 \% \downarrow$ CEL in RRMS & Phase II & Infusion reaction, allergies \\
\hline CTLA4Ig & $\begin{array}{l}\text { Prevents } \mathrm{T} \text { cell } \\
\text { activation }\end{array}$ & $\begin{array}{l}\text { IV }(2,10.0,20.0, \text { or } \\
35.0 \mathrm{mg} / \mathrm{kg})\end{array}$ & No significant changes & Phase I & $\begin{array}{l}\text { Lymphadenopathy, } \\
\text { urinary tract infections, } \\
\text { headaches, blurred vision, } \\
\text { and upper respiratory } \\
\text { tract infections }\end{array}$ \\
\hline \multicolumn{6}{|l|}{$\begin{array}{l}\text { Immune- } \\
\text { sequestration }\end{array}$} \\
\hline Fingolimod & $\begin{array}{l}\text { Sphingosine-I- } \\
\text { phosphate (SIP) } \\
\text { analog }\end{array}$ & $\begin{array}{l}\text { Oral ( }(1.25 \text { and } \\
5 \mathrm{mg})\end{array}$ & $80 \% \downarrow$ CEL, $50 \% \downarrow R R$ & Phase III & $\begin{array}{l}\text { Bradycardia, nasopharyn- } \\
\text { gitis, dyspnea, headaches, } \\
\text { diarrhea, nausea, } \\
\text { encephalitis, skin cancer }\end{array}$ \\
\hline SB-683699 & $\begin{array}{l}\text { Alpha-4 integrin } \\
\text { antagonist }\end{array}$ & $\begin{array}{l}\text { Oral (150-1200 mg } \\
\text { Twice Daily) }\end{array}$ & No data available & Phase II & No data available \\
\hline \multicolumn{6}{|l|}{$\begin{array}{l}\text { Unspecific } \\
\text { immunosupression }\end{array}$} \\
\hline Laquinimod & Antiinflammatory & Oral $0.6 \mathrm{mg} / \mathrm{d}$ & $40 \% \downarrow \mathrm{CEL}$ & Phase III & $\begin{array}{l}\text { LFT elevation, } \\
\text { Budd Chiari }\end{array}$ \\
\hline Fumaric acid (BGI2) & $\begin{array}{l}\text { Antiinflammatory/ } \\
\text { Neuroprotective }\end{array}$ & $\begin{array}{l}\text { Oral (I } 20-240 \mathrm{mg} \\
\text { TID) }\end{array}$ & $69 \% \downarrow \mathrm{CEL}$ & Phase III & $\begin{array}{l}\text { Diarrhea, cramps, nausea } \\
\text { and flushing }\end{array}$ \\
\hline Teriflunomide & $\begin{array}{l}\text { Inhibition of immune } \\
\text { cell proliferation }\end{array}$ & $\begin{array}{l}\text { Oral (7 and } 14 \mathrm{mg} \\
\text { dose) }\end{array}$ & $61 \% \downarrow C E L$ & Phase II & $\begin{array}{l}\text { Nasopharyngitis, alopecia, } \\
\text { nausea, limb pain, } \\
\text { diarrhea, and arthralgia }\end{array}$ \\
\hline
\end{tabular}

Abbreviations: RR, relapse rate; HZV, herpes zoster virus; HA, headaches; IV, intravenous; SAD, sustained acumulation of disability; ITP, immune thrombocytopenic purpura; SQ, subcutaneous; CEL, contrast enhancing MRI lesions; RRMS, relapsing remitting Multiple Sclerosis; LFT, liver function test.

A recent placebo-controlled Phase III trial using oral cladribine in patients with relapsing-remitting MS (RRMS), showed a $58 \%$ reduction in annualized relapse rates ( $3.5 \mathrm{mg} / \mathrm{kg}$ daily for four to five days, with two courses in the first year) at two years compared with placebo. In addition, $80 \%$ of patients remained relapse-free, compared with $61 \%$ of patients in the placebo group $(P<0.001$ for both dose regimens). Patients in the active drug group experienced a $30 \%$ reduction in the risk of disability progression relative to patients in the control group. ${ }^{6}$ Adverse events included headaches, nasopharyngitis, upper respiratory tract infections, and nausea. Lymphopenia occurred more frequently in the active drug group (22\%). Of the patients treated with cladribine tablets, $2.3 \%$ reported herpes zoster infections, although these were localized to the skin and were responsive to preventative treatment. A Phase III trial investigating oral cladribine in clinically isolated syndrome and a Phase IIb trial of combination therapy with interferon (IFN) $\beta$-1a is currently underway with an estimated date for completion of February 2010. Cladribine has the potential to be the first orally administered disease-modifying therapy available for patients with relapsing MS. As of December 2009 the FDA has not accepted Serono's approval application.

\section{Alemtuzumab}

Alemtuzumab is a humanized monoclonal antibody directed against CD52, a cell surface receptor expressed on lymphocytes, natural killer cells, monocytes, and macrophages. Alemtuzumab binds to B- and T- lymphocytes, resulting in antibody-dependent cell lysis, and subsequent elimination from the bone marrow and blood, with the effect lasting up to 16 months. Interestingly, the capacity of the immune cells 
to regenerate remains intact after repetitive drug cycles, but immature forms of B-cells (transitional type I cells) possibly driven by high B-cell activation factor levels are seen early in the course of immune reconstitution. This event could explain the association and development of antibody-mediated autoimmune disorders seen in the course of alemtuzumab therapy. Alemtuzumab is currently FDA-approved to treat B-cell chronic lymphocytic leukemia.

Studies of alemtuzumab in the treatment of patients with relapsing-remitting (RR) and secondary progressive MS (SPMS) have suggested efficacy in the suppression of annualized relapse rates, but with variable results in preventing progression of disability, depending on stages of the disease. In a recent Phase II randomized blinded clinical trial of intravenous (IV) alemtuzumab at $12 \mathrm{mg}$ per day or $24 \mathrm{mg}$ per day for five consecutive days during the first month and on three consecutive days at 12 and 24 months, alemtuzumab significantly reduced the rate of sustained accumulation of disability by $71 \%$, with a $74 \%$ reduction in the annualized rate of relapse compared with IFN $\beta$-1a in patients with early RRMS. Over $80 \%$ of patients receiving alemtuzumab remained relapse-free at 36 months. Reduction in $\mathrm{T}_{2}$ lesion volume and total brain volume analysis was greater in the alemtuzumab group. Adverse events in the alemtuzumab group included autoimmune thyroid disorders and thrombocytopenic purpura as well as infections. About one-third of patients develop antibodies against the thyrotropin receptor and subsequently develop autoimmune hyperthyroidism.? Currently there are two Phase III trials comparing two annual cycles of IV alemtuzumab with three times weekly IFN $\beta$-1a in treatment-naïve patients with RRMS (CARE-MS1 and CARE MS-2). These studies are expected to be completed in 2011 or 2012.

\section{Rituximab}

Rituximab is a chimeric antibody directed against human CD20 phosphoprotein present on all B-cell lineages except for stem cells, pro-B cells, and plasma cells. Rituximab acts by binding to B-cell lymphocytes, initiating a cascade of events that leads to B-cell lysis and subsequent depletion. The benefit of B-cell depletion in controlling the course of the disease supports the recently recognized active role of B-cells in the pathogenesis of MS. The standard dose of rituximab is $375 \mathrm{mg} / \mathrm{m}^{2}$ given weekly for four weeks, or a fixed dose of $2 \mathrm{~g}$ divided into two infusions of $1 \mathrm{~g}$ each two weeks apart. Following an IV administration of $2 \mathrm{~g}$ of rituximab, CD20 positive B-cells are rapidly depleted and remain undetectable for up to six months longer.
Rituximab has shown efficacy in the treatment of patients with RRMS. A recently completed randomized clinical trial using a standard dose of rituximab in RRMS patients demonstrated a $91 \%$ reduction in the number of gadoliniumenhancing lesions on (magnetic resonance imaging (MRI) scans, as well as a significant reduction in the number of clinical relapses. Mild infusion-related complications were seen in most patients, but serious adverse reactions were rare. ${ }^{8}$ In a recent trial of patients with primary progressive multiple sclerosis (PPMS), rituximab appeared to have efficacy only in young patients with signs of active inflammation on MRI scans. ${ }^{9}$ Five cases of progressive multifocal leukoencephalopathy have been recently reported in patients receiving rituximab for the treatment of rheumatoid arthritis and systemic lupus erythematosus. However, these patients were receiving other immunosuppresants.

Ocrelizumab, a humanized monoclonal antibody against human CD20, is currently under investigation in a Phase II trial evaluating its efficacy and safety in patients with RRMS. The estimated date of completion for this trial is $2012 .{ }^{10}$ Given the functional similarities between rituximab and ocrelizumamb, it is unclear which of these will be developed for use in MS.

\section{Daclizumab}

Daclizumab is a humanized mouse monoclonal antibody that binds to the alpha-subunit of the interleukin (IL)-2 receptor. This receptor is present on activated T- and B-cells but not on natural killer (NK) cells, and is crucial for T-cell proliferation and activation. The clinical benefit of daclizumab has been linked to significant expansion of immunoregulatory CD56 NK cells, and subsequent downregulation of adaptive T-cell responses (CD4 and CD8 positive T-cells). ${ }^{11}$ In an initial open-label study with IV daclizumab $1 \mathrm{mg} / \mathrm{kg}$, five patients with SPMS and six patients with RRMS demonstrated a decrease in number of contrast-enhancing lesions by $78 \%$ and in relapse rate by $81 \%$ compared with baseline. ${ }^{12} \mathrm{~A}$ recent open-label Phase II trial using subcutaneous daclizumab $2 \mathrm{mg} / \mathrm{kg}$ in MS patients with inadequate response to IFN $\beta$ therapy, demonstrated a $72 \%$ reduction in the number of new or enlarged contrast-enhancing lesions at week 24 compared with patients receiving IFN $\beta$ alone. Because Type I IFN is also known to enhance NK cell function, the question of possible synergism between IFN and daclizumab therapy is raised. ${ }^{13}$ Skin rash, chest discomfort, headaches, lymphopenia, generalized lymphadenopathy, and transient elevation of liver function tests and bilirubin levels have been reported. Daclizumab is already in clinical use to prevent rejection of 
kidney transplants. A multicenter Phase II trial investigating a subcutaneous formulation of daclizumab monotherapy is ongoing.

\section{CTLA-4 Ig}

CTLA-4Ig is a chimeric fusion protein that prevents T-cell activation by binding the B7-1 and B7-2 costimulatory molecules on antigen-presenting cells. A recent Phase I clinical trial showed that IV administration of CTLA-4Ig was well tolerated in patients with MS, and most adverse events were rated as mild. Lymphadenopathy, urinary tract infections, headaches, blurred vision, and upper respiratory tract infections were most frequently reported. Immunologic assessment of the patients showed a reduction in myelin basic protein proliferation within two months of infusion and decreased IFN- $\gamma$ production by myelin basic protein-specific lines. No significant changes in clinical or MRI parameters were observed during the study. ${ }^{14}$

\section{Immune sequestration}

\section{Fingolimod}

Fingolimod (FTY720), an oral sphingosine-1-phosphate (S1P) analog, acts as a partial agonist on S1P receptors, inducing internalization of the $\mathrm{S} 1 \mathrm{P}$ receptor, thereby blocking the mechanism necessary for lymphocytes to migrate out of secondary lymphoid structures. Fingolimod is associated with significant decreases in circulating T- and B-cells, particularly in central and naïve memory T-cells, with lesser reductions on effector memory T-cells. ${ }^{15}$ As a result of its lipophilic nature, fingolimod crosses the blood-brain barrier and possibly also downmodulates S1P1 in neural cells and astrocytes, thereby reducing astrogliosis, a phenomenon associated with neurodegeneration in MS. ${ }^{16}$

A recent multicenter, randomized, double-blind, placebocontrolled Phase III study with extension in RRMS patients demonstrated that oral fingolimod at doses of 1.25 and $5 \mathrm{mg}$, reduced the number of new focal inflammatory lesions by $80 \%$ and relapse rates by $50 \%$ compared with placebo. ${ }^{9}$ Over two years, the average annualised relapse rate in patients receiving fingolimod was $0.21,75 \%-77 \%$ of patients remained free of relapses, and $80 \%$ remained free of new enhancing MRI lesions. In addition, patients initially receiving placebo showed a marked improvement in clinical parameters of MS after switching to fingolimod in the extension study, which was sustained at month 24. Adverse reactions included bradycardia, nasopharyngitis, dyspnea, headaches, diarrhea, and nausea. Initial bradycardia was seen more frequently in the $5 \mathrm{mg}$ dose group. Three cases of basal cell carcinoma, three of squamous cell carcinoma, and one of melanoma were reported. Two fatalities occurred during the trial, and were associated with chicken pox and herpes virus infection. In addition, a single case of hemorrhagic encephalitis was reported but with an unclear causal relationship. Ongoing Phase III trials comparing the safety and efficacy of oral fingolimod $0.5 \mathrm{mg}$ and $1.25 \mathrm{mg}$ with IFN $\beta$-1a will soon yield results. ${ }^{17}$

\section{SB-683699}

SB-683699 is an oral medication that is thought to inhibit leukocyte trafficking across the blood-brain barrier by antagonism of alpha-4 integrins. A Phase II trial was recently completed in patients with RRMS evaluating the safety and efficacy of SB-683699 (150-1200 mg twice daily) in the development of MRI-confirmed new brain lesions at six months. Data from that trial will be available soon. ${ }^{18}$

\section{Non-specific immune modulation Laquinimod}

Laquinimod (quinoline-3-carboxamid) is a once-daily, orally administered immunomodulatory compound that is being developed as a disease-modifying treatment for RRMS. The anti-inflammatory properties of laquinimod are thought to be secondary to downregulation of major histocompatibility complex Class II gene transcription factors, stimulation of neurotrophin-3, neurotrophin-4 and brain-derived neurotrophic factor, activation of the anti-inflammatory IL-4 pathway in CD4+ cells, promotion of apoptosis in CD8+ and B-cells, and suppression of the metabolic activity of CD14+ and NK cells. As a consequence, there is a cytokine balance in favor of anti-inflammatory T-helper (Th)-2/Th-3 cytokines, with suppression of proinflammatory and cytokine-related genes. A Phase IIb study in 306 patients demonstrated that an oral daily $0.6 \mathrm{mg}$ dose of laquinimod significantly reduced MRI disease activity by a median of $60 \%$ versus placebo in RRMS patients. The majority of the patients that have participated in this trial are now receiving treatment with laquinimod in an open-label extension trial. ${ }^{19}$ An ongoing Phase III trial is currently evaluating the efficacy of laquinimod $0.6 \mathrm{mg}$ daily in patients with RRMS, with an estimated completion date of $2010 .^{20}$

Laquinimod appears to be well tolerated, with only transient and dose-dependent increases in liver enzymes. A case of Budd-Chiari syndrome occurred after one month of exposure in a patient with underlying hypercoagulability. Unlike its precursor substance, linomide, no cases of serositis or myocardial infarction have been reported so far in patients receiving laquinimod. 


\section{BG000 I 2}

BG00012 is an oral formulation of dimethyl fumarate that may exert a combination of anti-inflammatory and neuroprotective biological effects. Although its exact mechanism of action is not known, BG00012 is thought to inhibit immune cells by stimulating the expression of anti-inflammatory cytokines, such as IL-10, IL-4, and IL-5. Hence, it is thought that dimethyl fumarate can induce a shift from a Th-1 (pro-inflammatory) to a Th-2 (anti-inflammatory) T-cell response. ${ }^{21}$ In addition, BG00012 may have a neuroprotective therapeutic effect by inducing Phase II detoxification genes and upregulation of the Phase II detoxification enzyme, $\mathrm{NAD}(\mathrm{P}) \mathrm{H}$ :quinone oxidoreductase- $1 .{ }^{22}$

A previous multicenter, controlled clinical trial of oral BG00012 involving 257 people with RRMS receiving various doses of BG00012 capsules or placebo showed a dose-dependent reduction in active inflammation on MRI scans. ${ }^{23}$ Tolerability was good overall, with adverse events, including abdominal pain and flushing, more commonly occurring in the active treatment group. Two Phase III trials are currently ongoing evaluating if BG00012 is effective in reducing the proportion of relapses, decreasing the number of brain lesions, and slowing time to progression (DEFINE and CONFIRM). The estimated completion date for both studies is December 2010.

\section{Teriflunomide}

Teriflunomide is an inhibitor of mitochondrial dihydroorotate dehydrogenase, an enzyme critically involved in pyrimidine synthesis. Because activated lymphocytes largely depend on de novo pyrimidine synthesis, pyrimidine depletion might result in inhibition of immune-cell proliferation. ${ }^{24}$ There is some evidence from in vitro studies suggesting that teriflunomide induces Th-2-mediated anti-inflammatory cytokine activation.

Oral teriflunomide was tested in a randomized, doubleblind, placebo-controlled Phase II study. Patients with relapsing forms of MS were randomized to receive placebo, teriflunomide $7 \mathrm{mg}$ or $14 \mathrm{mg}$ a day for 36 weeks. Teriflunomide demonstrated a dose-dependent reduction in the number of $\mathrm{T}_{1}$-enhancing lesions. Teriflunomide was generally safe and well tolerated. Adverse effects included nasopharyngitis, alopecia, nausea, limb pain, diarrhea, and arthralgia. Hepatic necrosis and pancytopenia have been reported in patients with rheumatoid arthritis taking teriflunomide.

A two-year, double-blind, placebo-controlled Phase III study in relapsing MS is in progress. ${ }^{25}$ The primary outcome measure is relapse rate. Other ongoing or planned studies of teriflunomide include a Phase II study of combination with IFN- $\beta$, a Phase II study of combination with glatiramer acetate, and a placebo-controlled Phase III trial in clinically isolated syndrome. ${ }^{26-28}$

\section{Failed trials}

\section{Antigen-based immune therapies}

Induction of tolerance by antigen-based immune therapy appears to be a promising strategy in the treatment of autoimmune disorders. Recent studies evaluating the administration of a myelin basic protein-derived peptide (MBP8298) in patients with progressive forms of MS suggested a benefit in disease progression by clinical parameters in a subgroup of patients with HLA-DR2 and DR4 haplotypes. Two Phase II/III trials investigating MBP9298 in SPMS and RRMS patients with HLA-DR2 and four haplotypes were unfortunately negative. ${ }^{29,30}$ As of December 2009 there are no plans to restudy this molecule.

\section{IL- I 2 and IL-23 inhibitors}

IL-12 and IL-23 have been strongly implicated in the pathogenesis of MS. IL-23 is produced mainly by activated myeloid cells, and promotes and stabilizes IL-17 production by CD4+ T-cells, with subsequent tissue inflammation. Circulating mononuclear cells from patients with MS express increased concentrations of IL-12 and IL-23. Ustekinumab is a fully human monoclonal antibody against IL-12/23 p40 that neutralises IL-12 and IL-23. A Phase II, multicentre, randomised, double-blind, placebo-controlled study was done evaluating the administration of $27 \mathrm{mg}, 90 \mathrm{mg}$, or $180 \mathrm{mg}$ ustekinumab every four weeks or $90 \mathrm{mg}$ ustekinumab every eight weeks versus placebo. Unfortunately, this study did not demonstrate a significant benefit on formation of inflammatory white matter lesions or affect clinical events in patients with RRMS. ${ }^{31}$

\section{Atacicept}

Atacicept is an immunoglobulin fusion protein tumor necrosis factor family receptor transmembrane activator, calcium modulator, and cyclophilin ligand interactor which sequesters the B-cell survival factor, a proliferation-inducing ligand (APRIL), and B-lymphocyte stimulator of the tumor necrosis factor family (BLys) and thus inhibits later stages of B-cell development. A recent Phase II clinical trial evaluating efficacy and safety profiles in patients with MS was terminated because preliminary data suggested an increase in disease activity in patients receiving atacicept. ${ }^{32}$ 


\section{Remyelination and neural repair}

CNS remyelination is mostly mediated by oligodendrocyte progenitor cells. The ability to remyelinate is in general incomplete and fails over time. Many environmental factors play an important role in promoting or inhibiting myelin repair and oligodendrocyte differentiation. Of these, neurite outgrowth inhibitor Nogo-A, and its co-receptors TROY and LINGO-1 have been studied in both in vitro and in vivo studies..$^{33}$ Administration of anti-Nogo-A antibodies resulted in significant axonal growth in vitro and in animal models of spinal cord injury. ${ }^{34}$ Passive immunization with anti-Nogo-A antibodies in animal models of MS resulted in less demyelination and axonal damage compared with controls. ${ }^{35} \mathrm{~A}$ Phase I clinical open-label multicenter safety study evaluating continuous intrathecal administration of anti-Nogo-A antibody (ATI355) in patients with spinal cord injury is currently ongoing. The completion date is estimated to be November 2010. Overexpression of LINGO-1 inhibits oligodendrocyte differentiation and myelination, whereas attenuation of its function or administration of LINGO-1 antagonist antibody (anti-LINGO-1) enhances oligodendrocyte differentiation and myelination. ${ }^{36,37}$ In vivo studies demonstrated the presence of TROY and LINGO-1 in a subpopulation of reactive astrocytes, macrophages, and microglia in MS brain lesions. ${ }^{38}$ Treatment with an antibody antagonist to LINGO-1 function leads to functional recovery and increased integrity of axons in rats with experimental autoimmune encephalomyelitis induced by myelin-oligodendrocyte-glycoprotein. ${ }^{39}$ Studies of an anti-LINGO-1 monoclonal antibody are under consideration.

Cellular remyelinating strategies, involving both embryonic and neural stem cells, are being proposed as an elective source of brain cells for transplantation and potential therapies for MS. In vitro studies suggest that neuronal stem cells have the potential to restore neuronal activity and produce new neurons through transdifferentiation. Adult bone marrow-derived stromal cells were shown to induce similar immunomodulatory and neuroregenerative effects in the animal model of chronic experimental autoimmune encephalomyelitis. ${ }^{40,41}$ These concepts have led to an interest in the use of stem cells for neuronal regeneration and restoration of neurologic function in MS. To date, there are two clinical trials evaluating the use of autologous stem cells for the treatment of MS in humans. ${ }^{42,43}$

\section{Disclosure}

Augusto Miravalle, reports no conflicts of interest in this work. John R Corboy reports financial relationships/grant support from: NIH, National MS Society, Juvenile Diabetes Research Foundation, NIAID Immune Tolerance Network, Orasi, Novartis, Eli Lilly and Co, Peptimmune, Genentech.

\section{References}

1. Seto S, Carrera CJ, Kubota M, Wasson DB, Carson DA. Mechanism of deoxyadenosine and 2-chlorodeoxyadenosine toxicity to nondividing human lymphocytes. J Clin Invest. 1985;75(2):37-83.

2. Spurgeon S, Yu M, Phillips JD, Epner EM. Cladribine: Not just another purine analogue? Expert Opin Investig Drugs. 2009;18(8): 1169-1181.

3. Beutler E, Sipe JC, Romine JS, Koziol JA, McMillan R, Zyroff J. The treatment of chronic progressive multiple sclerosis with cladribine. Proc Natl Acad Sci U S A. 1996;93(4):1716-1720.

4. Rice GP, Filippi M, Comi G. Cladribine and progressive MS: Clinical and MRI outcomes of a multicenter controlled trial. Cladribine MRI Study Group. Neurology. 2000;54(5):1145-1155.

5. Romine JS, Sipe JC, Koziol JA, Zyroff J, Beutler E. A double-blind, placebo-controlled, randomized trial of cladribine in relapsing-remitting multiple sclerosis. Proc Assoc Am Physicians. 1999;111(1):35-44.

6. Serono E. CLARITY: A Phase III, randomized, double-blind, threearm, placebo-controlled, multi-center study to evaluate the safety and efficacy of oral cladribine in subjects with relapsing-remitting multiple sclerosis. NCT00213135.

7. Coles AJ, Compston DA, Selmaj KW, et al. Alemtuzumab vs interferon beta-1a in early multiple sclerosis. N Engl J Med. 2008;359(17): 1786-1801.

8. Hauser SL, Waubant E, Arnold DL, et al. B-cell depletion with rituximab in relapsing-remitting multiple sclerosis. $N$ Engl $\mathrm{J} \mathrm{Med}$. 2008;358(7):676-688.

9. Hawker K, O'Connor P, Freedman MS, et al. Rituximab in patients with primary progressive multiple sclerosis: Results of a randomized double-blind placebo-controlled multicenter trial. Ann Neurol. 2009;66(4):460-471.

10. Genentech HLR. Phase II, multicenter, randomized, parallel-group, partially blinded, placebo and Avonex controlled dose finding study to evaluate the efficacy as measured by brain MRI lesions, and safety of 2 dose regimens of ocrelizumab in patients with RRMS. NCT00676715.

11. Bielekova B, Catalfamo M, Reichert-Scrivner S, et al. Regulatory CD56 (bright) natural killer cells mediate immunomodulatory effects of IL-2R alpha-targeted therapy (daclizumab) in multiple sclerosis. Proc Natl Acad Sci U S A. 2006;103(15):5941-5946.

12. Bielekova B, Richert N, Howard T, et al. Humanized anti-CD25 (daclizumab) inhibits disease activity in multiple sclerosis patients failing to respond to interferon beta. Proc Natl Acad Sci U S A. 2004;101(23):8705-8708

13. Bielekova B, Howard T, Packer AN, et al. Effect of anti-CD25 antibody daclizumab in the inhibition of inflammation and stabilization of disease progression in multiple sclerosis. Arch Neurol. 2009;66(4):483-489.

14. Viglietta V, Bourcier K, Buckle GJ, et al. CTLA4Ig treatment in patients with multiple sclerosis: An open-label, phase 1 clinical trial. Neurology. 2008;71(12):917-924.

15. Mehling M, Brinkmann V, Antel J, et al. FTY720 therapy exerts differential effects on $\mathrm{T}$ cell subsets in multiple sclerosis. Neurology. 2008;71(16):1261-1267.

16. Brinkmann V. FTY720 (fingolimod) in multiple sclerosis: Therapeutic effects in the immune and the central nervous system. Br J Pharmacol. 2009;158(5):1173-1182.

17. Novartis. TRANSFORMS FTY720. A 12-month study comparing the efficacy and safety of two doses of fingolimod versus interferon $\beta$-1a in patients with relapsing-remitting multiple sclerosis with optional extension phase. NCT00340834. 
18. GlaxoSmithKline. Randomised, double-blind, placebo-controlled, parallel-group, dose-ranging study to investigate the MRI efficacy and the safety of six months' administration of SB-683699 in subjects with relapsing-remitting multiple sclerosis. NCT00395317.

19. Comi G, Pulizzi A, Rovaris M, et al. Effect of laquinimod on MRImonitored disease activity in patients with relapsing-remitting multiple sclerosis: A multicentre, randomised, double-blind, placebo-controlled phase IIb study. Lancet. 2008;371(9630):2085-2092.

20. Teva Pharmaceutical Industries. A multinational, multicenter, openlabel, single-assignment extension of the MS-LAQ-301 study, to evaluate the long-term safety, tolerability and effect on disease course of daily oral laquinimod $0.6 \mathrm{mg}$ in subjects with relapsing multiple sclerosis. NCT00988052.

21. de Jong R, Bezemer AC, Zomerdijk TP, van de Pouw-Kraan T, Ottenhoff TH, Nibbering PH. Selective stimulation of T helper 2 cytokine responses by the anti-psoriasis agent monomethylfumarate. Eur J Immunol. 1996;26(9):2067-2074.

22. Wierinckx A, Breve J, Mercier D, Schultzberg M, Drukarch B, Van Dam AM. Detoxication enzyme inducers modify cytokine production in rat mixed glial cells. J Neuroimmunol. 2005;166(1-2):132-143.

23. Schimrigk S, Brune N, Hellwig K, et al. Oral fumaric acid esters for the treatment of active multiple sclerosis: An open-label, baseline-controlled pilot study. Eur J Neurol. 2006;13(6):604-610.

24. Korn T, Magnus T, Toyka K, Jung S. Modulation of effector cell functions in experimental autoimmune encephalomyelitis by leflunomide - mechanisms independent of pyrimidine depletion. J Leukoc Biol. 2004;76(5):950-960.

25. Sanofi-Aventis. Long-term extension of the multinational, double-blind, placebo controlled study EFC6049 (HMR1726D/3001) to document the safety of two doses of teriflunomide ( 7 and $14 \mathrm{mg}$ ) in patients with multiple sclerosis with relapses. NCT00803049.

26. Sanofi-Aventis. A randomized, multinational, double-blind, placebocontrolled, parallel-group design pilot study to estimate the tolerability, safety, pharmacokinetics, and pharmacodynamic effects of teriflunomide for 24 weeks when added to treatment with glatiramer acetate in subjects with multiple sclerosis. NCT00475865.

27. Sanofi-Aventis. A randomized, multinational, double-blind, placebocontrolled, parallel-group design pilot study to estimate the tolerability, safety, pharmacokinetics, and pharmacodynamic effects of teriflunomide for 24 weeks when added to treatment with interferon-beta in subjects with multiple sclerosis. NCT00489489.

28. Sanofi-Aventis. An international, multi-center, randomized, doubleblind, placebo-controlled, parallel group study to evaluate the efficacy and safety of two year treatment with teriflunomide $7 \mathrm{mg}$ once daily and $14 \mathrm{mg}$ once daily versus placebo in patients with a first clinical episode suggestive of multiple sclerosis. NCT00622700.

29. Eli Lilly and Company. An open label follow-on study to assess the ongoing safety of MBP8298 in subjects with secondary progressive multiple sclerosis. NCT00870155.
30. Eli Lilly and Company. A double-blind, placebo controlled multicentre study to evaluate the efficacy and safety of MBP8298 in subjects with secondary progressive multiple sclerosis. NCT00869726.

31. Centocor I. A Phase II, double-blind, placebo-controlled, randomized, dose-ranging study of multiple subcutaneous injections of human monoclonal antibody to IL-12 p40 (CNTO1275) in subjects with relapsing-remitting multiple sclerosis. NCT00207727.

32. EMD Serono. An open-label, multicenter Phase II extension of study 28063 (ATAMS) to obtain long-term follow-up data in subjects with relapsing multiple sclerosis treated with atacicept for up to 5 years (ATAMS-Extension). NCT00853762.

33. Karnezis T, Mandemakers W, McQualter JL, et al. The neurite outgrowth inhibitor Nogo A is involved in autoimmune-mediated demyelination. Nat Neurosci. 2004;7(7):736-744

34. Liebscher T, Schnell L, Schnell D, et al. Nogo-A antibody improves regeneration and locomotion of spinal cord-injured rats. Ann Neurol. 2005;58(5):706-719.

35. Fontoura P, Ho PP, DeVoss J, et al. Immunity to the extracellular domain of Nogo-A modulates experimental autoimmune encephalomyelitis. J Immunol. 2004;173(11):6981-6992.

36. Mi S, Miller RH, Lee X, et al. LINGO-1 negatively regulates myelination by oligodendrocytes. Nat Neurosci. 2005;8(6):745-751.

37. Lee X, Yang Z, Shao Z, et al. NGF regulates the expression of axonal LINGO-1 to inhibit oligodendrocyte differentiation and myelination. J Neurosci. 2007;27(1):220-225.

38. Satoh J, Tabunoki H, Yamamura T, Arima K, Konno H. TROY and LINGO-1 expression in astrocytes and macrophages/microglia in multiple sclerosis lesions. Neuropathol Appl Neurobiol. 2007;33(1): 99-107.

39. Mi S, Miller RH, Tang W, et al. Promotion of central nervous system remyelination by induced differentiation of oligodendrocyte precursor cells. Ann Neurol. 2009;65(3):304-315.

40. Rafei M, Campeau PM, Aguilar-Mahecha A, et al. Mesenchymal stromal cells ameliorate experimental autoimmune encephalomyelitis by inhibiting CD4 Th17 T cells in a CC chemokine ligand 2-dependent manner. J Immunol. 2009;182(10):5994-6002.

41. Pluchino S, Quattrini A, Brambilla E, et al. Injection of adult neurospheres induces recovery in a chronic model of multiple sclerosis. Nature. 2003;422(6933):688-694.

42. Hadassah Medical Organization. Explorative trial to investigate the migration ability of mesenchymal bone marrow stem cells (MSC) in the central nervous system (CNS) following their intrathecal administration in severe cases of multiple sclerosis (MS). NCT00781872.

43. The Cleveland Clinic and University Hospital Case Medical Center. A Phase I study to assess the feasibility, safety, and tolerability of autologous mesenchymal stem cell transplantation in patients with relapsing forms of multiple sclerosis. NCT00813969.
Journal of Inflammation Research

\section{Publish your work in this journal}

The Journal of Inflammation Research is an international, peer-reviewed open-access journal that welcomes laboratory and clinical findings on the molecular basis, cell biology and pharmacology of inflammation including original research, reviews, symposium reports, hypothesis formation and commentaries on: acute/chronic inflammation; mediators of inflamma-

\section{Dovepress}

tion; cellular processes; molecular mechanisms; pharmacology and novel anti-inflammatory drugs; clinical conditions involving inflammation. The manuscript management system is completely online and includes a very quick and fair peer-review system. Visit http://www.dovepress.com/ testimonials.php to read real quotes from published authors. 